University of Montana

ScholarWorks at University of Montana

Numerical Terradynamic Simulation Group

Publications

Numerical Terradynamic Simulation Group

$5-2014$

\title{
Terrestrial hydrological controls on land surface phenology of African savannas and woodlands
}

Kaiyu Guan

Eric F. Wood

David Medvigy

John S. Kimball

University of Montana - Missoula

Ming Pan

See next page for additional authors

Follow this and additional works at: https://scholarworks.umt.edu/ntsg_pubs Let us know how access to this document benefits you.

\section{Recommended Citation}

Guan, K., E. F. Wood, D. Medvigy, J. Kimball, M. Pan, K. K. Caylor, J. Sheffield, X. Xu, and M. O. Jones (2014), Terrestrial hydrological controls on land surface phenology of African savannas and woodlands, $J$. Geophys. Res. Biogeosci., 119, 1652-1669, doi:10.1002/2013JG002572

This Article is brought to you for free and open access by the Numerical Terradynamic Simulation Group at ScholarWorks at University of Montana. It has been accepted for inclusion in Numerical Terradynamic Simulation Group Publications by an authorized administrator of ScholarWorks at University of Montana. For more information, please contact scholarworks@mso.umt.edu. 


\section{Authors}

Kaiyu Guan, Eric F. Wood, David Medvigy, John S. Kimball, Ming Pan, Kelly K. Caylor, Justin Sheffield, Xiangtao $\mathrm{Xu}$, and Matthew $\mathrm{O}$. Jones 


\section{Journal of Geophysical Research: Biogeosciences}

\author{
RESEARCH ARTICLE \\ 10.1002/2013JG002572 \\ Key Points: \\ - African tropical woodlands green-up \\ before the onset of rainy season \\ - Phenology of African woodlands may \\ be influenced by groundwater \\ - Rainy season length has nonlinear \\ impacts on tropical tree fractional cover
}

Supporting Information:

- Readme

- Text $\mathrm{S1}$

- Figure $\mathrm{S1}$

- Figure S2

- Figure 53

- Figure $\$ 4$

- Figure 55

- Figure 56

- Figure 57

Correspondence to:

K. Guan,

kaiyug@stanford.edu

Citation:

Guan, K., E. F. Wood, D. Medvigy,

J. Kimball, M. Pan, K. K. Caylor, J. Sheffield,

$\mathrm{X} . \mathrm{Xu}$, and M. O. Jones (2014), Terrestrial

hydrological controls on land surface

phenology of African savannas and

woodlands, J. Geophys. Res. Biogeosci.,

119, doi:10.1002/2013JG002572.

Received 18 NOV 2013

Accepted 19 APR 2014

Accepted article online 1 MAY 2014

\section{Terrestrial hydrological controls on land surface phenology of African savannas and woodlands}

\author{
Kaiyu Guan ${ }^{1,2}$, Eric F. Wood', David Medvigy ${ }^{3}$, John Kimball ${ }^{4,5}$, Ming Pan', Kelly K. Caylor', \\ Justin Sheffield ${ }^{1}$, Xiangtao $\mathrm{Xu}^{3}$, and Matthew O. Jones ${ }^{4,5}$ \\ ${ }^{1}$ Department of Civil and Environmental Engineering, Princeton University, Princeton, New Jersey, USA, ${ }^{2}$ Department of \\ Environmental and Earth System Science, Stanford University, Stanford, California, USA, ${ }^{3}$ Department of Geosciences, \\ Princeton University, Princeton, New Jersey, USA, ${ }^{4}$ Flathead Lake Biological Station, University of Montana, Polson, \\ Montana, USA, ${ }^{5}$ Numerical Terradynamic Simulation Group, University of Montana, Missoula, Montana, USA
}

\section{Introduction}

"Vegetation phenology" refers to the periodic biological life cycle events of plants, such as leaf flushing and senescence, and corresponding temporal changes in vegetation canopy cover [Stöckli et al., 2011]. This concept is linked tightly with plant establishment, growth, and reproduction [Morisette et al., 2009; Scheiter and Higgins, 2009] and also connects to the biosphere-atmosphere fluxes of energy, water, and carbon [Bonan, 2008]. Thus, vegetation phenology has critical significance to ecosystem functioning and associated services. Global warming has advanced the biological spring and lengthened the Northern Hemisphere growing season [Zhou et al., 2001; Myneni et al., 1997], because temperature is a dominant trigger for vegetation phenology in temperate ecosystems [Nemani et al., 2003]. These changes have large impacts on the regional carbon budgets [Richardson et al., 2010; Piao et al., 2008] and may have complex feedback to climate [Richardson et al., 2013]. However, it remains less clear how climate change has altered and will alter vegetation phenology in water-limited ecosystems, and associated implications for carbon cycling and climate feedback. Future climate is expected to transform precipitation patterns in a complex way [Weltzin et al., 2003; Trenberth et al., 2003], with changes in the rainy season projected over various water-limited regions of the world. For example, shortening and a seasonal shift in the rainy season have been projected for the Sahel [Biasutti and Sobel, 2009] and southern Africa [Shongwe et al., 2009], which imposes urgency for better understanding about how climate and surface hydrological processes control vegetation phenology in water-limited ecosystems. This urgency is exemplified in Africa, where dryland/semidryland ecosystems cover more than $60 \%$ of the continental landmass, and large uncertainties remain in predicting ecosystem responses to rainfall regime shifts in concert with other climatic changes [Giannini et al., 2008; Higgins and Scheiter, 2012]. 

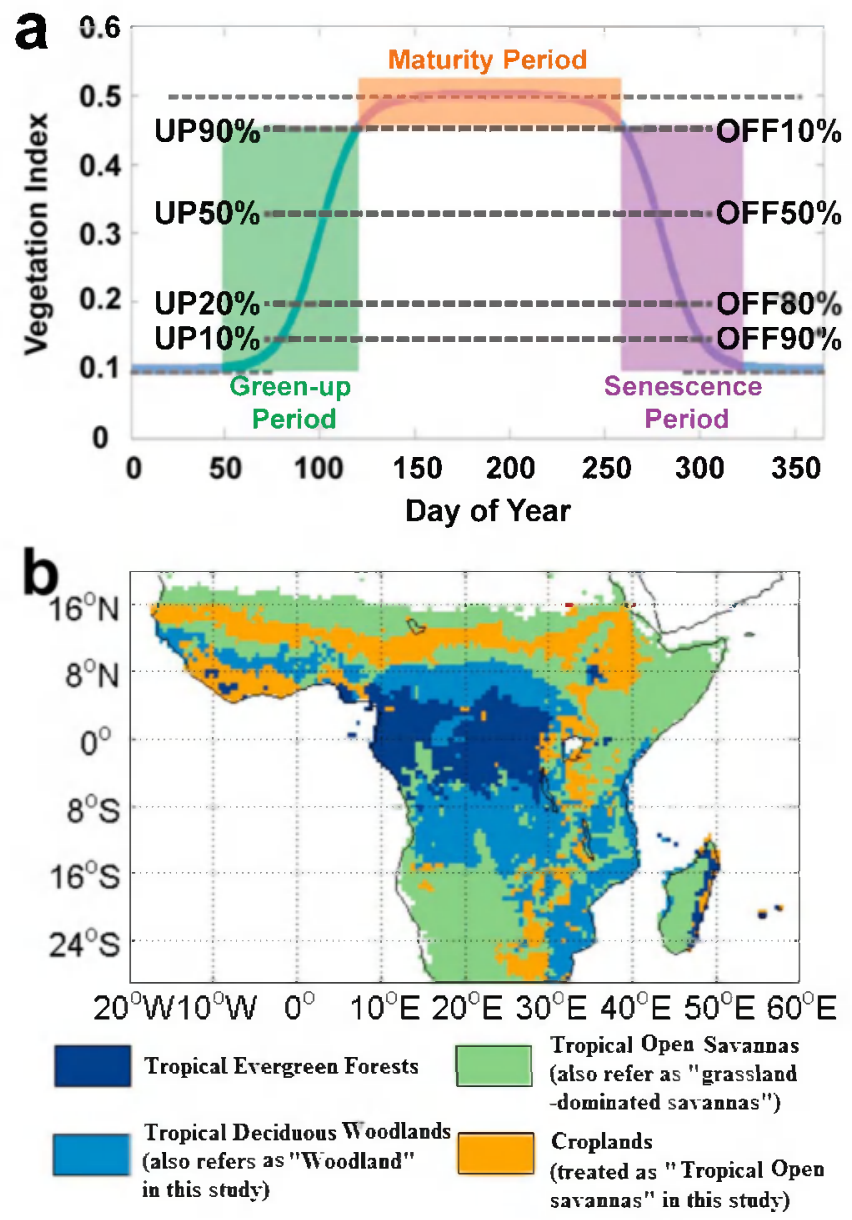

Figure 1. (a) Definition of land surface phenological phases used in this study. (b) Simplified land cover map based on the GLC2000 Africa [Mayaux et al., 2004].
Empirically studying the relationship of climate and vegetation phenology requires the availability of reliable data at proper spatial scales. Satellite remote sensing provides relatively consistent measurements of a range of land surface phenology attributes across space and time, which makes it possible to analyze large-scale patterns of vegetation phenology and its relationship with climate. Satellite remote sensing measures spatially integrated vegetation attributes over variable footprints ranging from approximately $100 \mathrm{~m}$ to $25 \mathrm{~km}$; this landscape level metric is termed "land surface phenology (LSP)" [Morisette et al., 2009]. It is worth noting that this definition differs from the traditional vegetation phenology, which is usually based on in situ observations of individual plants or species. LSP is a combined signal of phenological behaviors of many individual plants in a landscape; thus, it also contains landscape and structural information (e.g., fraction of tree/grass/bare soil). We define various phases of LSP from time series of remotely sensed vegetation indices (e.g., Figure 1a), which are used as proxies of regional vegetation growth, senescence, and dormancy at the satellite pixel scale

[Zhang et al., 2003]. Previous LSP studies over Africa have primarily involved analyzing optical and near-infrared (NIR)-based spectral vegetation greenness indices, including the NDVI (normalized difference vegetation index) and EVI (enhanced vegetation index); these studies include analyzing spatial gradients in phenological dates [Zhang et al., 2005; Camberlin et al., 2007], phenological trajectory differences in different biomes and climate [Martiny et al., 2006; Guan et al., 2013], temporal trends in phenological dates [Tateishi and Ebata, 2004; Linderman et al., 2005; Heumann et al., 2007; Vrieling et al., 2013], and attributions of phenology behavior to rainfall [Philippon et al., 2005], temperature and humidity [Brown et al., 2012], and large climate oscillations [Brown et al., 2010]. Studies explicitly assessing interannual variability between the rainy season and regional vegetation phenology are lacking, and very few studies have addressed the temporal advances or lags among different phases of the rainy season and growing season. Filling these gaps has become possible only recently as synergistic satellite data records for precipitation and vegetation have accumulated over more than a decade, attaining a minimum length for statistical analysis of interannual relationships.

Our previous study [Guan et al., 2013] demonstrated that African savannas and woodlands, unlike tropical evergreen forests, have clear phase correspondence between the rainy season and vegetation growing season; i.e., they are largely overlapping in time. However, this temporal correspondence is mostly driven by the strong impacts of dry season, during which lack of moisture shuts down most plant physiological and metabolic activities in dryland and semidryland ecosystems. In addition, this first-order seasonal correspondence could not explain what specific environmental factors trigger canopy leaf flushing and senescence and what factors control interannual variability in these phenological properties. For example, early leaf flushing in the African Miombo Woodlands has been widely observed before the arrival of seasonal rainfall [Chidumayo, 1994; Fuller and Prince, 1996; Seghieri et al., 2012a, 2012b], with delayed 
senescence in many woody species after the end of the rainy season [Bie et al., 1998; Seghieri et al., 1995]. These unresolved phenological behaviors call for a more detailed study on the relationships between the rainy season and regional land surface phenology, including canopy growth onset and senescence.

Tropical savannas are mostly water limited and are characterized by the coexistence of grasses and trees [Scholes and Archer, 1997], which may have different life cycle strategies and phenological responses. Grasses (mostly $C_{4}$ in Africa) usually follow the "pulse-reserve" paradigm [Noy-Meir, 1973] and opportunistically use water resources whenever is available to support their growth; the phenological response of these grasslands is expected to closely track shallow soil moisture dynamics [Scanlon et al., 2005]. While woody vegetation species may initiate growth using stored carbon reserves acquired during the previous season [Scheiter and Higgins, 2009], they may also have the ability to access other water resources (e.g., groundwater or stem-water reserve) to sustain vegetation activity during the dry season [Bie et al., 1998] and develop more complex desiccation tolerance and desiccation resistance structures through deeper roots, stem-water storage, etc. [Pineda-Garcia et al., 2012]. These features may indicate a different and more complex phenological response beyond the pulse-reserve paradigm. The ecological niche separation of water resource use in both space (i.e., root depth [Walter, 1939; Ward et al., 2013]) and time (i.e., phenology [Higgins et al., 2011]) may contribute to the tree-grass coexistence pattern in tropical savannas. Thus, analyzing the heterogeneous phenological responses in conjunction with hydrological processes across large regional gradients in climate and biome distribution is critical for developing better vegetation phenology mechanism in vegetation dynamic models for water-limited ecosystems.

As the rainy season provides the temporal niche for favorable vegetation growth conditions in African dryland and semidryland ecosystems, it is also important to understand how the length of rainy season impacts ecosystem productivity or structure. Highly seasonal rainfall can reduce the rate of canopy closure [Schimper, 1903; Sarmiento, 1984] and facilitate grass expansion [Lloyd et al., 2008] and can increase fire frequency [Archibald et al., 2009; Lehmann et al., 2011; Staver et al., 2011]. In particular, from the hydrological perspective, the same amount of rainfall occurring over different time spans can have variable impacts on the partitioning of the terrestrial water budget (e.g., transpiration, evaporation, and runoff) and influence vegetation growth, and rainy season length may explain regional patterns in vegetation phenology and tree cover. An important question is whether tree fractional cover increases monotonically with longer rainy season. Recent modeling studies [Feng et al., 2012; Rohr et al., 2013] have found that rainy season length has a nonlinear impact on vegetation productivity from a hydrological perspective. This paper will present a possible empirical evidence for this theory.

This paper empirically studies relationships between rainy season and LSP seasonal phases and interannual variability across African savanna and woodland ecosystems. We examine spatial and temporal relations between rainy season length and vegetation onset and senescence periods, and associated impacts on vegetation structure (i.e., tree fraction), by employing multiple synergistic satellite-derived vegetation and hydrological data records, and hydrological model simulations for the period from 2000 to 2010 . This investigation is motivated by the following questions: (1) How does the timing of the rainy season (i.e., onset/offset) influence land surface phenology of woodlands and open savannas in Africa, including LSP seasonal and interannual variability? (2) How do variations in rainy season length influence tree cover and associated ecosystem structure across the region? The paper first introduces the data sets and LSP-extraction methods used for the analysis (section 2) and then presents pixel-level time series of remotely sensed vegetation status and hydrological variables for selected representative pixels over the study area (section 3.1). We then focus on analyzing continental-scale relationships between the start (end) of the rainy season and start (end) of the growing season in sections 3.2 and 3.3, respectively. Section 3.4 presents an empirical pattern related to the nonlinear impacts of rainy season length on fractional tree cover, followed by general discussions and conclusions on the significance of these results.

\section{Materials and Methods}

This study focuses on understanding the relationship between land surface phenology and the rainy season for vegetated regions of Africa between $20^{\circ} \mathrm{N}$ and $30^{\circ} \mathrm{S}$ that display a unimodal growing season. In this domain, water availability has a dominant influence on vegetation dynamics [Nemani et al., 2003; Guan et al., 2013]. Land cover within the study domain is dominated by tropical deciduous woodlands (also referring as 
"woodlands" in this study) and tropical open savanna (also referring as "savannas" hereafter, see Figure 1b), with some cropland areas mainly clustered in the Sahel region. The major differences between "tropical deciduous woodlands" and "tropical open savannas" are whether there is a closure of tree canopy in the landscape [Lehmann et al., 2011]. In this study, we group African cropland areas into the tropical open savannas. Physiologically, most Africa crops are $C_{4}$ plants, most African croplands are fragmented and mixed with natural savannas, and there is very little irrigated agriculture in the region, so we can assume that croplands and grasslands would have similar phenology patterns. Other African vegetated regions (north of $20^{\circ} \mathrm{N}$ or south of $30^{\circ} \mathrm{S}$ ) are excluded in this study because these areas reflect Mediterranean climate conditions, with relatively dry summers and rainy winters, and both temperature and water supply can influence vegetation phenology [Peel et al., 2007]. We distinguished between regions with single or multiple growing seasons using Fourier power spectra, following Guan et al. [2014].

\subsection{Data Set}

2.1.1. NDVI

We used the daily NDVI calculated from red $(620-670 \mathrm{~nm})$ and near-infrared $(841-876 \mathrm{~nm})$ spectral reflectance bands of the Moderate Resolution Imaging Spectroradiometer (MODIS) MOD09CMG product (Collection 5, level 3) [Vermote et al., 2011]. This global data set has been corrected to reduce the effects of atmospheric gases and aerosols. Only best possible data retrievals (i.e., quality control flag of the first 2 bits is 00 or 01 ) are used in the study. The original $0.05^{\circ}$ spatial resolution of the MOD09CMG product was aggregated to $0.1^{\circ}$ in this study. The daily temporal resolution is the primary reason for choosing this data set over other MODIS vegetation index products available at coarser 8- 16 day temporal resolution. The MODIS record for years 2000 to 2011 is used in this study. Due to the noisy conditions of the daily NDVI data set, a fitting preprocessing to recover the envelope of the time series [Chen et al., 2006] was used before implementing the phenological extraction algorithm.

\subsubsection{Microwave Vegetation Optical Depth}

We used a satellite passive microwave remote sensing-based vegetation optical depth (VOD) product [Jones et al., 2010, 2011] from the Advanced Microwave Scanning Radiometer for EOS (AMSR-E) to assess phenological changes in vegetation canopy biomass structure [Guan et al., 2012]. The VOD parameter is a frequency-dependent measure of canopy attenuation of microwave emissions, which represents changes in vegetation biomass and water content [Ulaby et al., 1982; Jones et al., 2013a, 2013b]. The VOD record has been used as an additional canopy phenology measure that is sensitive to both photosynthetic and nonphotosynthetic (e.g., woody) biomass [Jones et al., 2011; Guan et al., 2012], whereas the MODIS NDVI record primarily detects changes in canopy-top photosynthetic vigor or potentials. We used the near-daily $10.7 \mathrm{GHz}$ frequency VOD retrievals at the constant incidence angle of $55^{\circ}$ from nadir from an existing AMSR-E global land parameter database for ecosystem studies [Jones and Kimball, 2010]. A detailed description of the AMSR-E VOD record, including algorithm development and sensitivity, can be found in Jones et al. [2010, 2011]. In this study, we used the daily VOD record from 2003 to 2011 , and a robust smoothing algorithm [Garcia, 2010] was applied to gap-fill missing values and smooth the daily time series. The original $0.25^{\circ}$ spatial resolution was interpolated to $0.1^{\circ}$ for the analysis.

\subsubsection{Tree Fractional Cover Data}

In this study we use satellite-derived tree fractional cover as a metric of ecosystem structure pertaining to the relative abundance of woody vegetation cover. We used a tree fractional cover data set based on the algorithm of Guan et al. [2012] by combining satellite active microwave data (Ku band backscattering coefficient from QuikSCAT [Long, 2001]) and passive optical-NIR reflectance data (MODIS EVI [Solano et al., 2010]). This product represents an integration of optical-NIR and active microwave remote sensing based on the mean vegetation state and interannual vegetation sensitivity to precipitation. This product outperformed the MODIS vegetation continuous fields (VCF) product [Hansen et al., 2003] when compared with tree fractions derived from high-resolution imagery for natural vegetation [Guan et al., 2012]. However, our analysis indicates that use of our tree fractional cover data or MODIS VCF data (not shown) generate similar relationships between tree cover and rainy season length (section 3.4); thus, the relevant finding is independent of the tree fractional cover data that are used.

\subsubsection{TMPA Precipitation Data}

We used gridded precipitation data from the version 3B42V6 Tropical Rainfall Measurement Mission (TRMM) Multisatellite Precipitation Analysis (TMPA) [Huffman et al., 2007]. The TMPA 3B42V6 is a 3 hourly, $0.25^{\circ}$ 
product based on multisatellite retrievals that combine microwave and infrared remote sensing estimates and are rescaled to match monthly gauge observations using histogram matching [Huffman et al., 2007]. The TMPA product was converted from its original $0.25^{\circ}$ and 3 hourly resolution to a $0.1^{\circ}$ and daily resolution for the 2000-2011 data record for this study.

\subsubsection{VIC-Simulated Soil Moisture}

Measurements of large-scale soil moisture are only available from satellite microwave-based soil moisture products either derived from remotely sensed brightness temperatures from passive radiometries [Jackson, 1993] or active backscattering from scatterometers [Wagner et al., 1999]. However, these soil moisture retrievals are only sensitive to water content shallower than approximately $3 \mathrm{~cm}$ in the top layer of the soil column, while the soil moisture signal is degraded under higher vegetation biomass levels [Njoku and Entekhabi, 1996]; this limits capabilities for studying soil hydrology and vegetation dynamics given that most vegetation (especially trees) in Africa can be sensitive to much deeper soil moisture levels [Do et al., 2005, 2008; Seghieri et al., 2012a, 2012b]. Here we used simulated soil moisture from a macroscale hydrological model, variable infiltration capacity (VIC) [Liang et al., 1994]. The VIC model simulates subdaily terrestrial water and energy balances and represents subgrid variability in soil water storage capacity as a spatial probability distribution [Liang et al., 1994]. The VIC model has been applied extensively at regional [e.g., Maurer et al., 2002] and global scales [e.g., Nijssen et al., 2001; Sheffield and Wood, 2007]. The VIC model was used in this study to generate the retrospective soil moisture profile at two soil depths: $0-10 \mathrm{~cm}$ and $10 \mathrm{~cm}$ to $1 \mathrm{~m}$. The TMPA rainfall record (interchangeable with "TRMM rainfall" hereafter in this paper) [Pan et al., 2010] and other climate variables from the Global Meteorological Forcing Dataset of Princeton University [Sheffield et al., 2006] were used to force the VIC model for the period from 2000 to 2010 running at $0.25^{\circ}$ resolution and 3 hourly time step [Pan et al., 2012], with calibrated model parameters from Sheffield and Wood [2007], which further refined the coarse soil texture and hydrology-related properties at local scales. The soil moisture output was interpolated to $0.1^{\circ}$ resolution and daily time step for the analysis. It is worth noting that the VIC model-simulated soil moisture is only used here for diagnostic analysis rather than prognostic purposes.

\subsubsection{Gravity Recovery and Climate Experiment Terrestrial Water Storage}

The terrestrial water storage variations captured by the Gravity Recovery and Climate Experiment (GRACE) satellite were used to study the potential interactions between subsurface water storage changes and land surface phenology. The GRACE satellite measures the total change in the terrestrial water storage (including surface and ground water elements, and water stored in vegetation) through associated changes in the Earth's gravity field [Rodell and Famiglietti, 2002; Tapley et al., 2004]. The terrestrial water storage from the GRACE is found to be highly correlated with the changes in soil moisture and groundwater in various ecosystems [Strassberg et al., 2009; Pokhrel et al., 2013]. Vegetation biomass signals are 1 to 2 orders of magnitude smaller than atmospheric and other terrestrial influences and have little contribution to overall changes in the GRACE gravity field [Rodell et al., 2005]. Thus, the GRACE terrestrial water storage retrieval can be safely interpreted as an independent measure of subsurface water storage changes. We used the GRACE monthly land water mass grids (TELLUS_LAND_NC_RL05) global data record from Jet Propulsion Laboratory [Swenson and Wahr, 2006], which has a monthly time step and $1^{\circ}$ spatial resolution, and has been processed using a $200 \mathrm{~km}$ radius Gaussian filter. The resulting GRACE data record from 2002 to 2011 is used in the current study.

\subsection{Extraction of Vegetation Phenological Information}

We used a newly derived algorithm [Guan et al., 2014] to extract LSP information from the daily MODIS (MOD09CMG) NDVI record. This new algorithm fits a double-logistic curve to a daily input time series, which is similar to the MODIS phenological algorithm [Zhang et al., 2003], but with a more rigorous mathematical derivation and better boundary constraints. The algorithm provides all the necessary information to reconstruct the whole trajectory of a daily time series and thus can provide more user-defined phenological timing criteria. In this study, we extracted the $10 \%, 20 \%, 50 \%$, and $90 \%$ thresholds of the seasonal range for both green-up and senescence periods (Figure 1a). We define the period when NDVI is above $90 \%$ of its range as the "maturity period," and $n \%$ UP refers to the time when NDVI reaches $n \%$ of the seasonal range for the "green-up period," which includes the whole period of the increasing phase in NDVI trajectory; $m \%$ OFF refers to the time when NDVI drops to $m \%$ of the range from the peak value in the "senescence period," which refers to the entire descending period of the NDVI trajectory. Using multiple phenological thresholds provides a more complete depiction of land surface phenology and also provides a way to quantify 
uncertainties in interpreting phenological information extracted from coarse-/medium-resolution remote sensing, given that there is still a lack of understanding regarding relationships between satellite-derived LSP observations and finer-scale ground truth information [White et al., 2009; Jones et al., 2013a, $2013 \mathrm{~b}$ ].

\subsection{Extraction of Rainy Season Timing Information}

There is no consensus on the definition of the rainy season and its onset and end time [Marengo et al., 2001; Wang and LinHo, 2002]. Here we define rainy season starts at the time that the cumulative rainfall reaches a certain climatological percentile of mean annual precipitation (so-called "Percentage approach") in a "hydrological year" using gridded daily rainfall data on a per pixel basis. The hydrological year starts in the middle of the dry season, followed by the rainy season, and ends in the subsequent dry season; this definition applies to regions with only a single annual rainy season. The hydrological year is determined as follows: the TRMM multiyear mean daily rainfall data were temporally smoothed with a lengthening smoothing window size until there were only two inflection points for the first-order derivative of the smoothed time series corresponding to midpoints of the wet and dry seasons. Once determined, the hydrological year was fixed thereafter for each year. We then applied the definitions for onset and end of rainy season to each hydrological year on a per pixel basis. The rainy season onset date is defined when the cumulative rainfall of the selected year reaches a climatological threshold of 5\% (or 10\%) of the mean total annual rainfall; the rainy season end date occurs when the total rainfall from that date to the end of the hydrological year reaches a climatological threshold of $5 \%$ (or $10 \%$ ) of annual rainfall. The use of the climatological percentile is convenient to apply to the entire study area, which spans a large annual rainfall gradient.

It is worth noting that there are other definitions of rainy season. For example, the AGRHYMET [1996] (also in Brown and de Beurs [2008]) defines the rainy season onset as the first day that the subsequent 10 days have at least $25 \mathrm{~mm}$ of total rainfall, followed by another 20 days with at least $20 \mathrm{~mm}$ of total rainfall; if the second condition is not fulfilled, testing for the next day is resumed. We checked differences between the AGRHYMET approach and the Percentage approach (Figure S1 in the supporting information) and found that both yield similar spatial patterns over Africa and the absolute differences are very small that they do not change the resulting patterns and the conclusion.

\section{Results}

\subsection{Seasonal Patterns of Hydrological and Phenological Variables at Pixel Scale}

The 4 year time series (2003-2006) of hydrological variables (TRMM precipitation, VIC two-layer soil moisture, GRACE water storage changes) and vegetation status from the satellite NDVI and VOD series from eight representative pixels across the study domain are presented in Figure 2, while the locations of the pixels are shown in Figure 3c. The following major findings are summarized in Figure 2:

1. The seasonal VOD and NDVI trajectories are tightly coupled for grassland (e.g., Figures $2 \mathrm{a}$ and $2 \mathrm{~h}$ ); these two trajectories deviate in woodland areas, and the temporal disparity between VOD and NDVI increases with tree fraction [Jones et al., 2012], with VOD exhibiting relatively slower increase at the beginning of the growing season and delayed peak time. This pattern is consistent with the physical basis of these observations and with previous studies: NDVI is related to canopy photosynthetic activity [Sellers et al., 1992; Guan et al., 2012], which generally responds quickly to environmental changes as demonstrated by a relatively rapid NDVI increase at the beginning of the growing season. For the plants with low biomass (leaf area index $(\mathrm{LAI})<3.5$ ), NDVI is highly correlated with LAI or vegetation aboveground biomass. In contrast, the VOD is sensitive to canopy-volume biomass and water content, including photosynthetic and nonphotosynthetic (e.g., woody) canopy biomass components, and exhibits a slower characteristic seasonal response than the NDVI [Jones et al., 2012]. The late peak of VOD indicates that regional plant biomass generally reaches its seasonal peak at the end of the rainy season. Thus, in grassland, VOD, and NDVI are closely tracking to each other because the biomass and photosynthesis rates codevelop and have almost linear correlation under its low biomass volume; however, the large disparity between VOD and NDVI in woodland indicates the lags of biomass accumulation after the photosynthesis rhythm in tree-dominated landscape, which usually contains much larger plant biomass.

2. Though the NDVI covaries with rainfall seasonality, in general, the initial seasonal increase in NDVI may precede the rainy season onset (e.g., in woodlands, Figures $2 \mathrm{c}$ and $2 \mathrm{e}$ ) or lag behind it (e.g., in open savannas, Figures $2 \mathrm{a}$ and $2 \mathrm{~g}$ ). NDVI also persists for various amount of time following the end of the rainy 
a

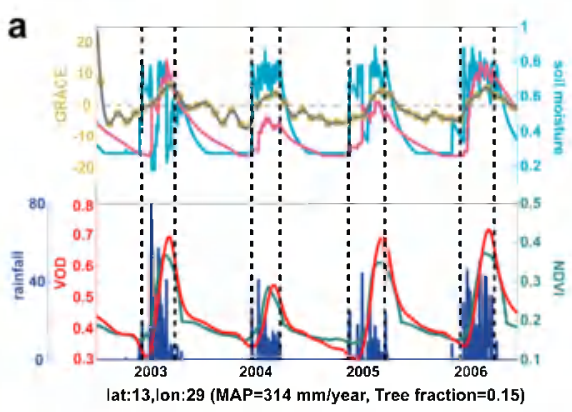

C

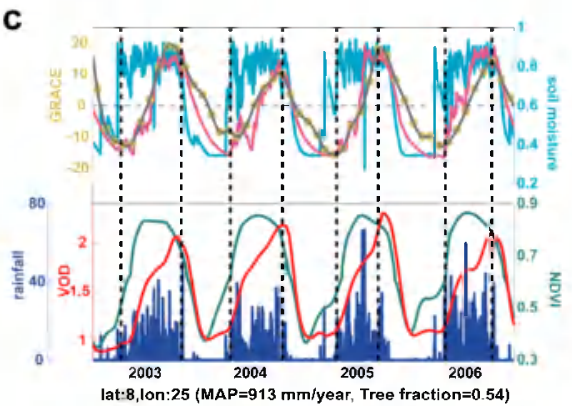

e

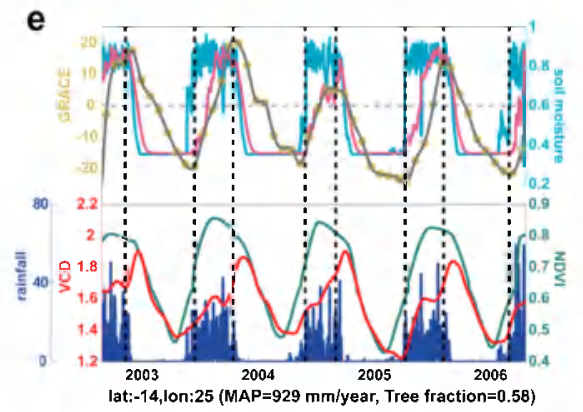

g

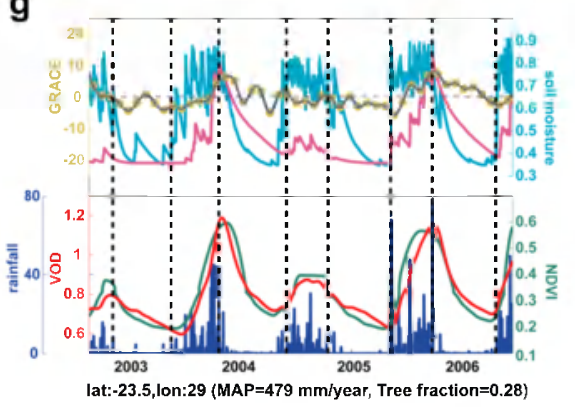

b

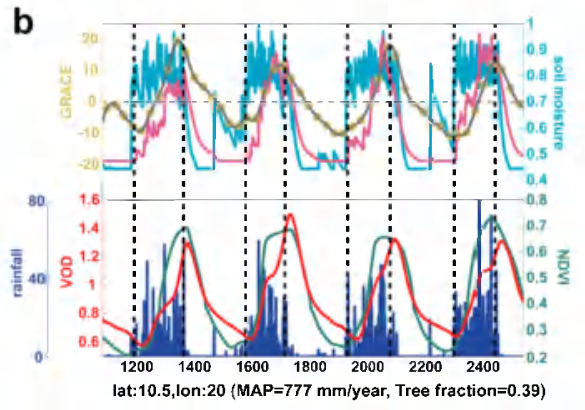

d

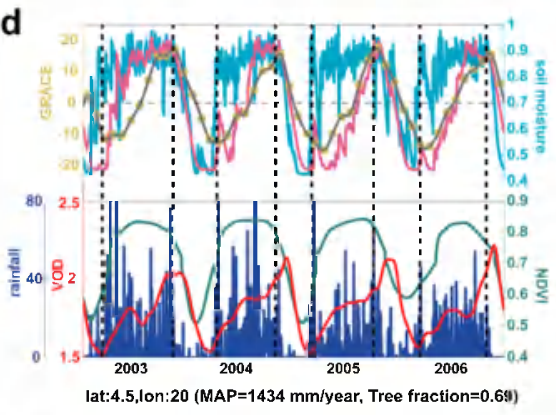

f

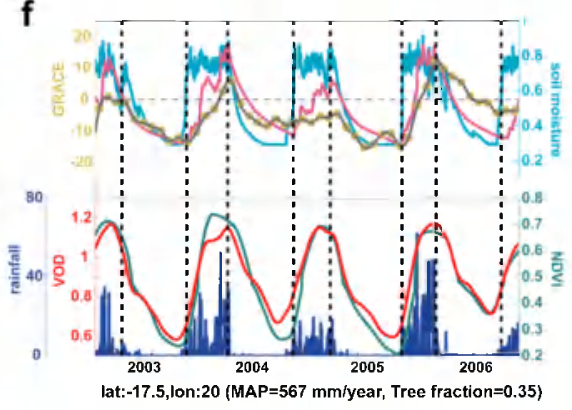

h

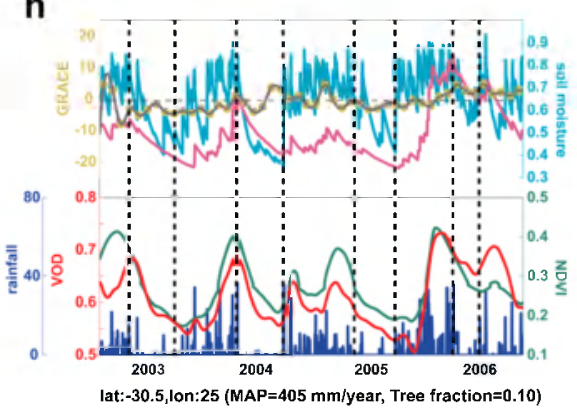

Figure 2. Time series of hydrological and vegetation variables for selected representative pixels across the African domain. Satellite-derived variables include vegetation optical depth (VOD) from AMSR-E (red), GRACE-derived terrestrial water storage (dark yellow), TRMM-/TRMM Microwave Imager (TMI)-derived rainfall (blue bars), and MODIS-derived NDVI (green); soil moisture at two layers $(0-10 \mathrm{~cm}$ and $10 \mathrm{~cm}-1 \mathrm{~m}$, blue and magenta, respectively) is derived from a macroscale hydrological model $(\mathrm{VIC})$. The corresponding locations of the selected pixels are in Figure $3 \mathrm{c}$.

season before reaches to full senescence (indicated as NDVI90\%OFF) as shown in all the representative pixels in Figure 2. These patterns indicate that the rainy season alone may not fully explain African woodland phenology, while other terrestrial hydrological processes, propagated from rainfall, may play a significant role in explaining temporal offsets between the vegetation growing season and rainy season in different biomes.

3. For the hydrological variables, seasonal phase differences are evident between precipitation, first- and second-layer soil moisture, and subsurface water storage anomalies (Figure 2). The first-layer soil moisture 
(a) DOY of NDVI20\%UP

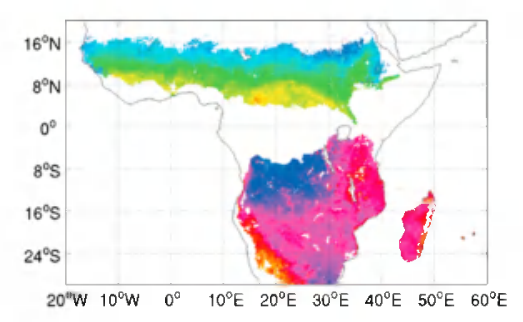

(b) DOY of TRMM5\%Cumu

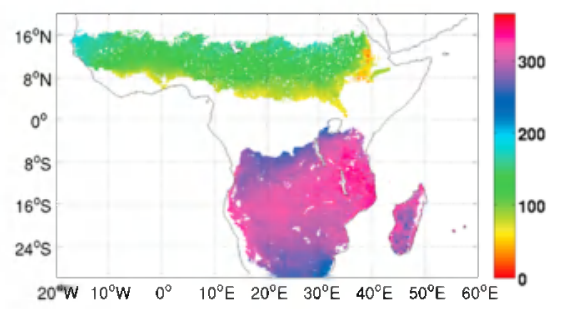

(c) Difference in days (NDVI20\%UP-TRMM5\%Cumu)

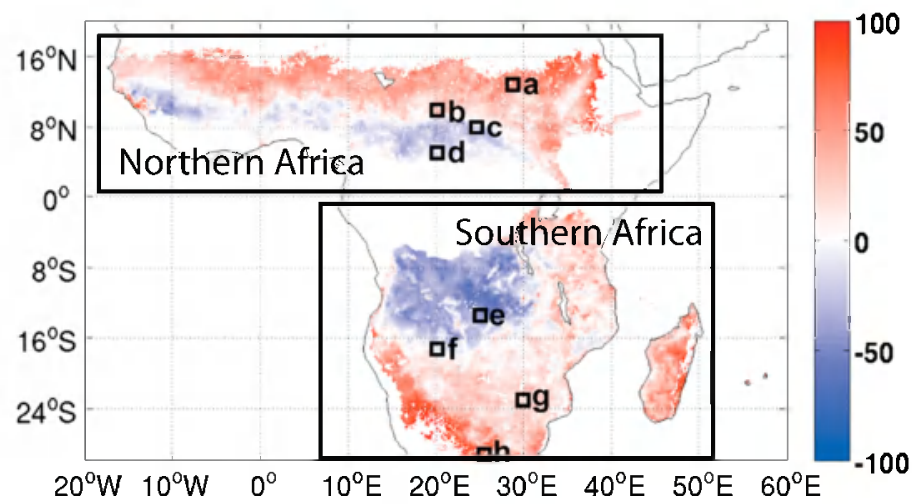

(d) Northern Africa

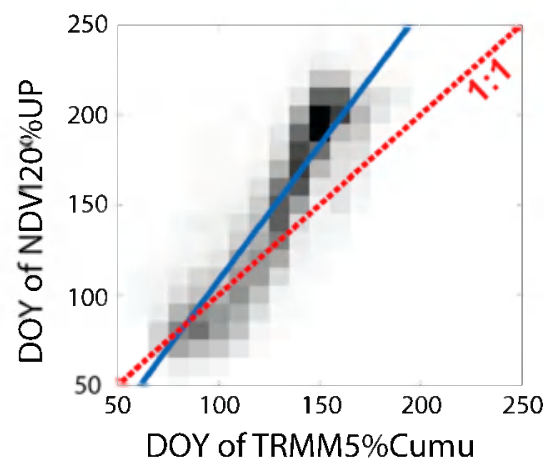

(e) Southern Africa

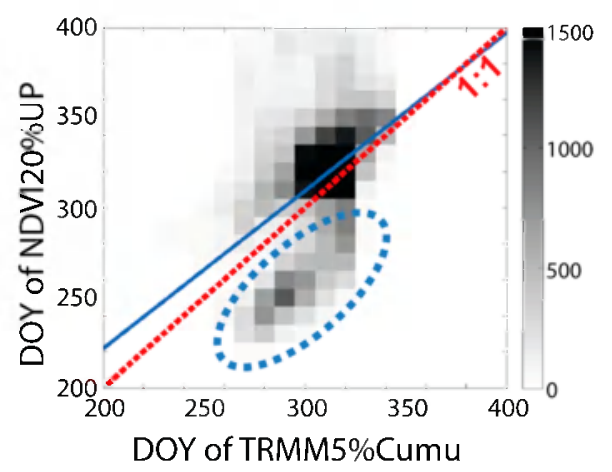

Figure 3. Relationship between satellite-observed growing season and rainy season onset defined from respective MODIS NDVI and TRMM/TMI precipitation observations over African grassland and savanna; areas outside of the domain in Figures $3 a-3 c$ are shown in white. (a) The growing season onset is defined here as the day (day of year (DOY)) when NDVI reaches $20 \%$ in its seasonal green-up phase, and (b) the rainy season onset is defined as the DOY when rainfall reaches $5 \%$ of the annual accumulation of climatological Mean Annual Precipitation (MAP). (c) The pixel-wise differences between the onset of growing season and rainy season, and the small black squares denote locations of representative pixels shown in Figure 2. ( $\mathrm{d}$ and e) The pixel scatter density plots between the two onset times for the northern Africa and southern Africa, whose regions have been delineated in Figure $3 c$; the blue line is the linear regression between the onsets of rainy season and growing season, and the red dashed line refers to the 1:1 line.

sharply increases following the rainy season onset (indicated by the dashed black line) and also quickly decays after the end of the rainy season. The deeper second-layer soil moisture seasonality lags behind the shallower first-layer and has a slower decline following the end of the rainy season. Seasonal changes in regional subsurface water storage (including both soil moisture and groundwater) from GRACE show the largest phase lags with precipitation, especially in woodland areas. Here we interpret the period of increasing terrestrial water storage (TWS) from GRACE as the "recharging phase," which indicates that water storage is replenished from rainfall inputs; similarly, decreasing TWS from GRACE indicates a "releasing phase" where water storage is being withdrawn. We find that the releasing phase in most 
woodland areas generally persists into the dry season when the estimated first/second layer of soil moisture has been depleted (i.e., soil moisture in these layers reaches a seasonal minimum), possibly indicating that water storage deeper than $1 \mathrm{~m}$ may be being steadily withdrawn during the remainder of the dry season.

\subsection{Start of Rainy Season and Growing Season at the Continental Scale}

The relationships between the regional rainy season and growing season onset are described below. The spatial patterns of rainy season and growing season onset averaged over the 2000 to 2010 record are presented in Figure 3. These results are summarized separately for Northern Hemisphere Africa and Southern Hemisphere Africa because the rainfall seasonalities of these two regions are reversed and are also controlled by different climate systems [Nicholson, 1996].

We find that the onset dates of both TRMM-derived rainy season and NDVI-derived growing season show similar spatial gradients for both Southern Hemisphere and Northern Hemisphere Africa. The Northern Hemisphere Africa shows clear latitudinal correspondence in these two onset dates $\left(R^{2}=0.53, p<0.05\right.$, Figure $3 \mathrm{~d})$; however, the Southern Hemisphere Africa has much lower correlation in space $\left(R^{2}=0.17, p=0.12\right.$, Figure 3e), which is consistent with the finding of Zhang et al. [2005] based on 2 year MODIS phenological product. The major reason for the southern-northern difference is that the Northern Hemisphere Africa has one dominate weather system (i.e., Intertropical Convergence Zone (ITCZ) [Giannini et al., 2008]), while the Southern Hemisphere Africa has more complex weather system (including east-west oriented component of the African ITCZ originated from the northern inland and the Indian Ocean and the westerly current which originates over the South Atlantic [McHugh and Rogers, 2001; Nicholson, 1996; Cook, 2000]), which makes spatial pattern of the rainfall onset/end more complex.

One common feature for northern and southern Africa is that there are a significant number of pixels showing early NDVI green-up before rainy season onset, and this pattern does not change when using different thresholds for defining the growing season (NDVI 10\%UP, NDVI 20\%UP) and rainy season metrics (TRMM 5\% cumulative, TRMM 10\% cumulative; see Figure S2 in the supporting information). This pattern is evident in the southern Africa, as two distinct relationship regimes are apparent between NDVI growing season and TRMM precipitation onset (Figure 3e), with one regime clustering largely below the 1:1 line (blue dashed polygon in Figure 3e), where growing season onset generally occurs before the start of the rainy season. These two regimes are coincident with regional distribution of woodlands and open savannas, respectively (Figure $1 \mathrm{~h}$ ). For the whole African study area, the early green-up regions encompass approximately $32 \%$ of the study domain (Figure 3c) and largely overlap with woodlands (e.g., Figures $1 \mathrm{~b}$ and $7 \mathrm{~d}$ ). The difference between the onsets of rainy season and growing season is inversely correlated with tree fraction (Figure $7 \mathrm{~d}, R^{2}=0.73, p<0.0001$ ), indicating that ecosystem structure can explain most spatial variance in vegetation phenology. These results confirm numerous other studies that have found many savanna tree species to green-up before the onset of the rains [Borchert, 1994; Fuller and Prince, 1996; Do et al., 2005; Higgins et al., 2011; Seghieri et al., 2012a, $2012 \mathrm{~b}$ ].

Two major mechanisms can possibly explain this early green-up in woodlands. One is the access to the groundwater through deep root systems found in many tropical deciduous trees [Schenk and Jackson, 2002; Roupsard et al., 1999], and the other is the stem-water reserve that stored in tree trunks or roots [Borchert, 1994] to support dry season green-up. Though in this study we do not have any field data to support the second mechanism, the GRACE data provide some possible evidence for the first mechanism. The GRACE TWS changes (Figures $2 \mathrm{C}$ and $2 \mathrm{e}$ ) indicate that subsurface water is still being withdrawn in the dry season when simulated shallow soil moisture has been depleted (i.e., there would be very little soil evaporation). The phase differences between GRACE data and simulated shallow soil moisture may support that some tropical deciduous trees can use deeper groundwater resources to sustain dry season vegetation activity.

We also study the interannual variability of onset dates for rainy season and growing season. We find that woodlands generally have much smaller interannual variability than grasslands for both onset dates (Figures 4a, $4 b, 53$, and S4). Since the majority of woodlands have green-up before the onsets of rainy season, we expect that only open savannas may show some power of using rainy season onsets to predict growing season onsets. It turns out that only open savannas southern Africa have high correlations between the onsets of rainy season and growing season (Figures 4 and S6), with a weaker and more dispersed correlation pattern in northern Africa, mostly due to the low interannual variability of rainy season onsets in the northern Africa (Figure 4b). 

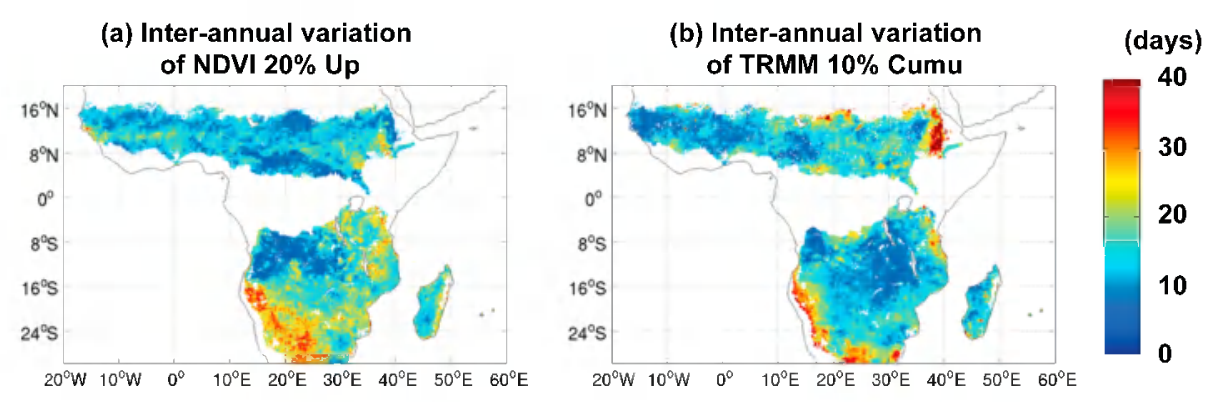

(c) Inter-annual correlation between NDVI onset and rainy season onset

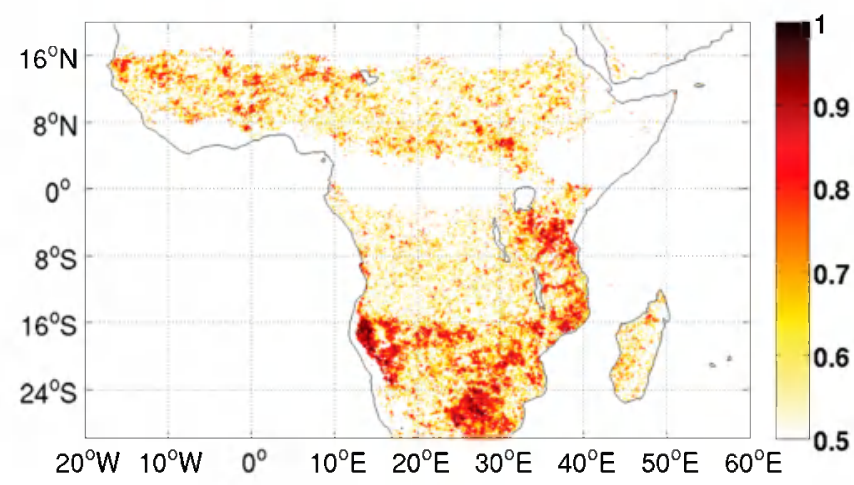

Figure 4. Interannual variability (standard deviation) and correlation between growing season and rainy season onsets defined from the MODIS NDVI and TRMM/TMI precipitation series over African grassland and savanna areas; areas outside of the domain are shown in white. (a) The interannual variation of growing season onset (interannual variation of NDVI20\%UP). (b) The interannual variation of rainy season onset (the interannual variation of TRMM10\%cumulative). (c) The composited correlation between rainy season and growing season onsets (also see Figure $\mathrm{S} 6$ in the supporting information).

\section{(a) DOY of NDVI $10 \%$ Off}

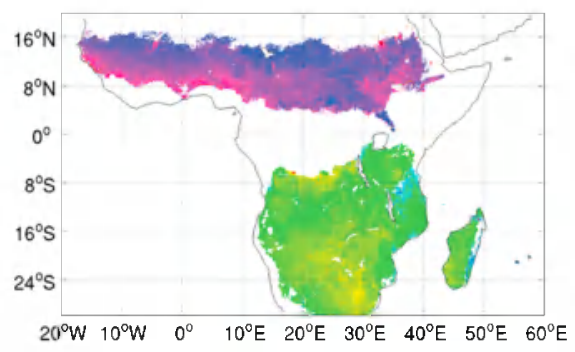

(c) DOY of TRMM 95\% Cumu

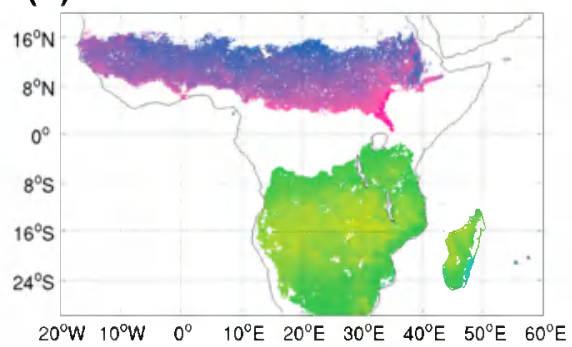

(b) DOY of NDVI $90 \%$ Off

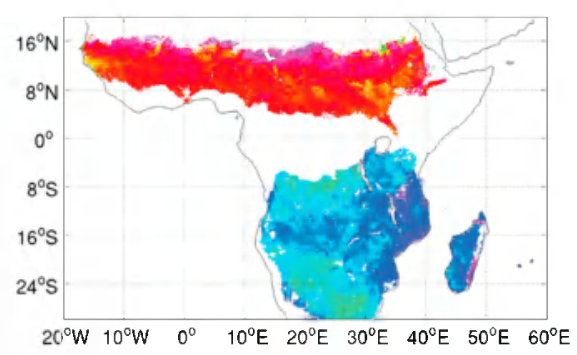

(d) DOY of VOD Peak

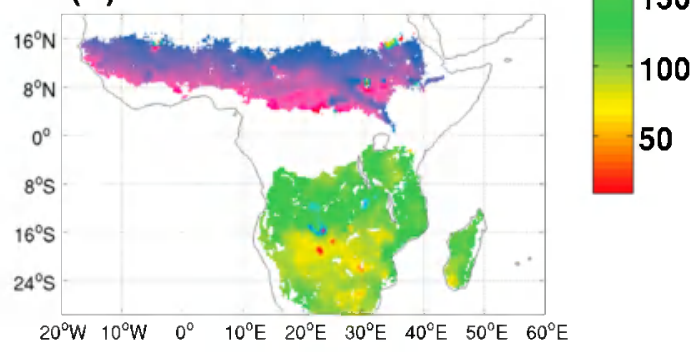

Figure 5. Satellite data-derived senescence phases of vegetation and end of rainy season: (a) the DOY of NDVI 10\%OFF from MODIS, (b) DOY of NDVI 90\%OFF from MODIS, (c) DOY of TRMM 95\% cumulative, and (d) DOY of VOD peak. 
(a)

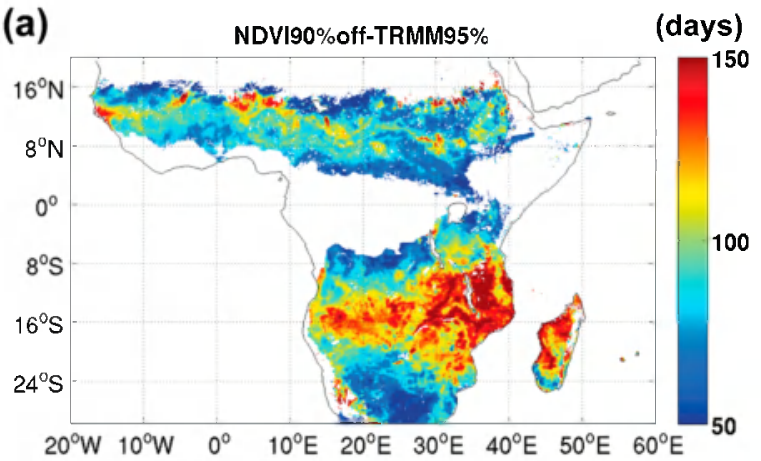

(b)

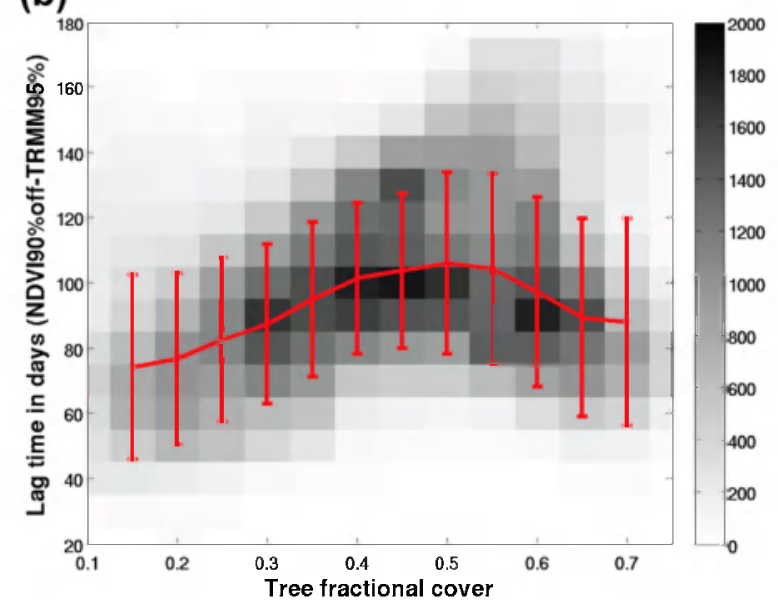

Figure 6. (a) Temporal lag (days) between vegetation full senescence (NDVI90\%OFF) and the end of the rainy season (TRMM95\%cumulative) determined from MODIS NDVI and TRMM precipitation, respectively, over the African domain. The corresponding relationship between tree fractional cover [Guan et al., 2012] and (b) the lag time for all pixels in the domain.
Since rainy season onset does not cue on the start of the growing season (e.g., leaf flushing) in woodlands, other environmental cues may trigger leaf flushing of woodlands, such as photoperiod, insolation, or vapor pressure deficit [Do et al., 2005; Seghieri et al., 2012a, 2012b].

\subsection{End of Rainy Season and Growing Season at the Continental Scale}

We now focus on the end of the growing season and its associated environmental control. The regional satellite observations indicate that NDVI senescence has temporal lags of various lengths after the end of rainy season (section 3.1). Across the whole Africa, the end of seasonal canopy maturity (i.e., NDVI 10\%OFF and estimated start of senescence, Figure 5a) generally coincides with the timing of the VOD peak (indicating the timing of maximum canopy biomass, Figure $5 \mathrm{~d}$ ), while both of these metrics coincide with the end of the rainy season estimated from the TRMM (Figure 5c). However, the end of the vegetation senescence period (i.e., NDVI 90\%OFF, Figure 5b) largely lags behind the end of the rainy season. These results are also consistent with the pixel level patterns in Figure 2.

We further quantify the NDVI senescence lag length by calculating the temporal difference between NDV190\%OFF and the

end of the rainy season, as shown in Figure 6 . Figure $6 \mathrm{~b}$ indicates that when tree fractional cover is below 0.5 , the senescence lag time increases with greater tree fractional cover. In contrast, when the tree fraction is larger than 0.5 , the senescence lag time decreases with increasing tree fractional cover. The positive correspondence between senescence lag and tree cover when tree fraction is below 0.5 may indicate a greater extent of deep-rooted trees capable of either accessing deeper groundwater resources or have stemwater reserve that enable a longer period of plant activity after the rainy season ends and surface soil moisture is depleted. However, this correlation pattern does not hold when tree fraction is above 0.5 , which is mostly correspondent to the transitional regions from deciduous woodlands to evergreen forests. In these regions, rainy season lengths are significantly longer than the neighboring regions (Figure 7a), but growing season lengths remain similar to other woodlands as they are reaching saturation (with upper bound of 365 days, Figure $7 \mathrm{~b}$ ). In other words, in these regions, keeping lengthening rainy season does not further increase tree fraction cover as the latter reaches saturation. This explains why there is a weak decreasing trend in Figure $6 \mathrm{~b}$ when tree fraction is above 0.5 .

We also studied the temporal correspondence between the end of rainy season and other growing season phases. The end of the rainy season was poorly correlated with both the end of canopy maturity (NDVI10\%OFF) and the end of canopy senescence (NDV190\%OFF) (results not shown). The low correspondence is primarily attributed to low interannual variability in both the rainy season ending time (Figure S5 in the supporting information) and vegetation senescence phases (Figure $\$ 4$ in the supporting information). The vegetation senescence period of African woodlands generally exhibits little interannual variation (Figure S4, standard deviation $<10$ days), which indicates that canopy senescence in tropical woodlands is not very responsive to 

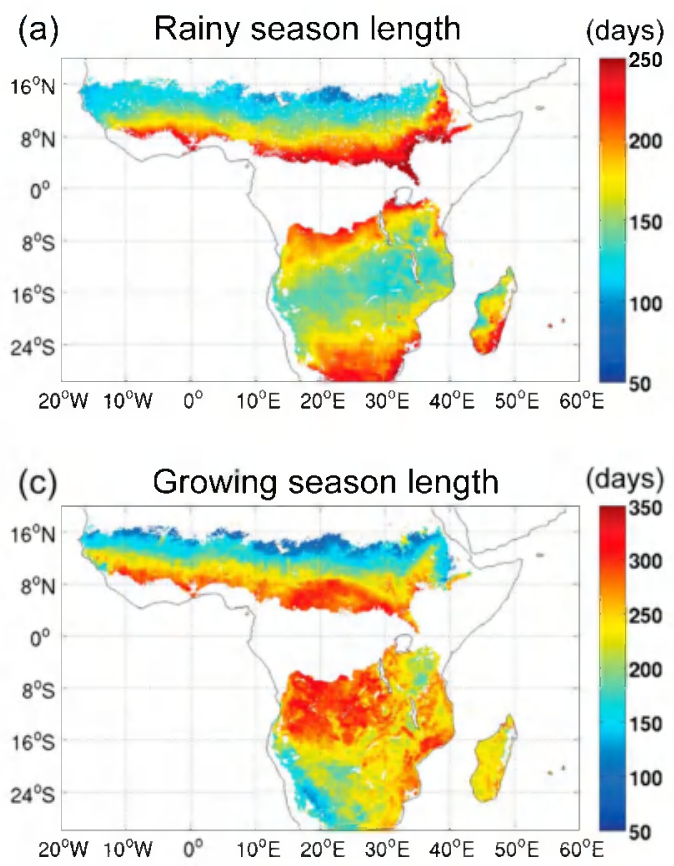

(b) Mean annual precipitation (mm/year)
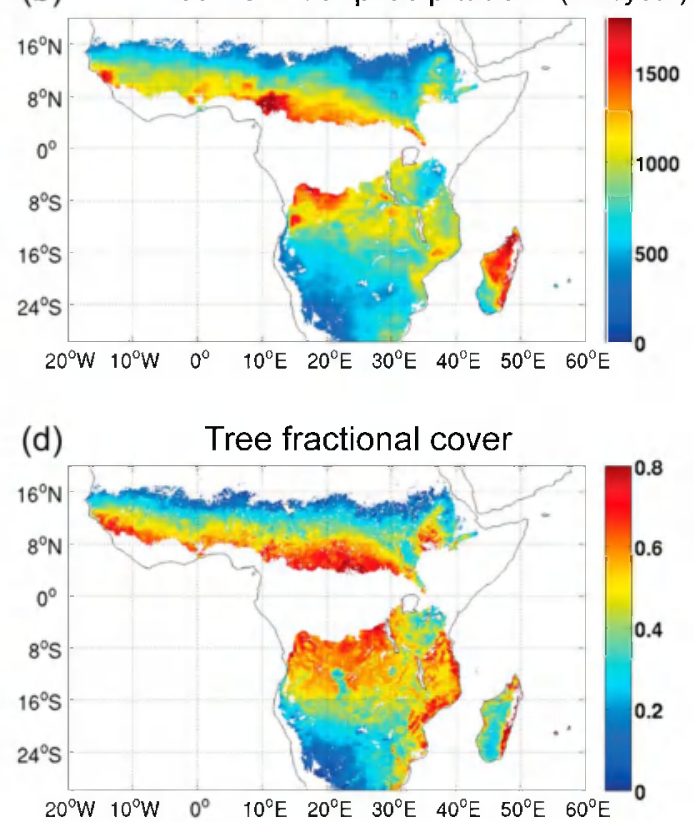

Figure 7. (a) Rainy season length (i.e., the difference between TRMM95\%cumulative and TRMM5\%cumulative). (b) Mean annual precipitation. (c) Growing season length (i.e., the difference between NDVI20\%OFF and NDVI20\%UP). (d) Tree fractional cover [Guan et al., 2012].

rainy season. Instead, senescence in these areas may be controlled by photoperiod or insolation-related environmental cues that show almost no interannual variation [Yeang, 2007; Borchert et al., 2005].

\subsection{Nonlinear Impacts of Rainy Season Length on Tree Fraction Cover}

Previous studies indicate a positive linear relationship between growing season length and tree fractional cover over Africa ( $r=0.73, p<0.05$ [Guan et al., 2014]). The results of the current study confirm this general relationship (Figures $7 c$ and $7 d$ ). However, the linkage between rainy season length and tree fraction is not clear and has not been explicitly addressed in previous studies. We further find that tree fractional cover does not simply correlate with mean annual precipitation or rainy season length within the African domain (e.g., Figure 7). Instead, we find a nonlinear response of tree fractional cover to mean annual precipitation and rainy season length (Figure 8a), which confirms the previous modeling studies by Feng et al. [2012] and Rohr et al. [2013] that are mostly based on the plant water use. Here we define rainy season length as the period encompassing $90 \%$ of the total annual rainfall climatology. For rainfall regimes below $600 \mathrm{~mm} / \mathrm{yr}$ and above $1800 \mathrm{~mm} / \mathrm{yr}$, tree fractional cover is directly proportional to mean annual precipitation. However, for intermediate rainfall regimes (i.e., $600 \mathrm{~mm} / \mathrm{yr}$ to $1800 \mathrm{~mm} / \mathrm{yr}$ ), tree fractional cover shows a nonlinear response to rainy season length: for a fixed mean annual precipitation, tree fraction increases with rainy season length until reaching a maximum proportional cover, where the corresponding rainy season length is denoted as the rainy season "optimal length," tree cover then decreases with further increase of rainy season (see the inset of Figure 8a).

The nonlinear impacts of rainy season length on tree fractional cover may originate from various reasons [Schimper, 1903; Lloyd et al., 2008; Lehmann et al., 2011; Staver et al., 2011]. As Feng et al. [2012] and Rohr et al. [2013] have found from a hydrological perspective, given the same amount of total annual rainfall, the length of rainy season (and inversely the length of dry season) can influence water budget partitioning and rainfall use efficiency (defined as the percentage of rainfall ended up for plant growth through transpiration) [Huxman et al., 2004] and can impact vegetation dynamics. For the same amount of total rainfall, as rainy season increases from very short to longer period, less runoff would be expected and more rainfall would be used as transpiration and facilitate tree growth, and rainfall use efficiency would increase with the lengthening of the rainy season. However, when rainy season keeps increasing to be very long, more rainfall may be ended 

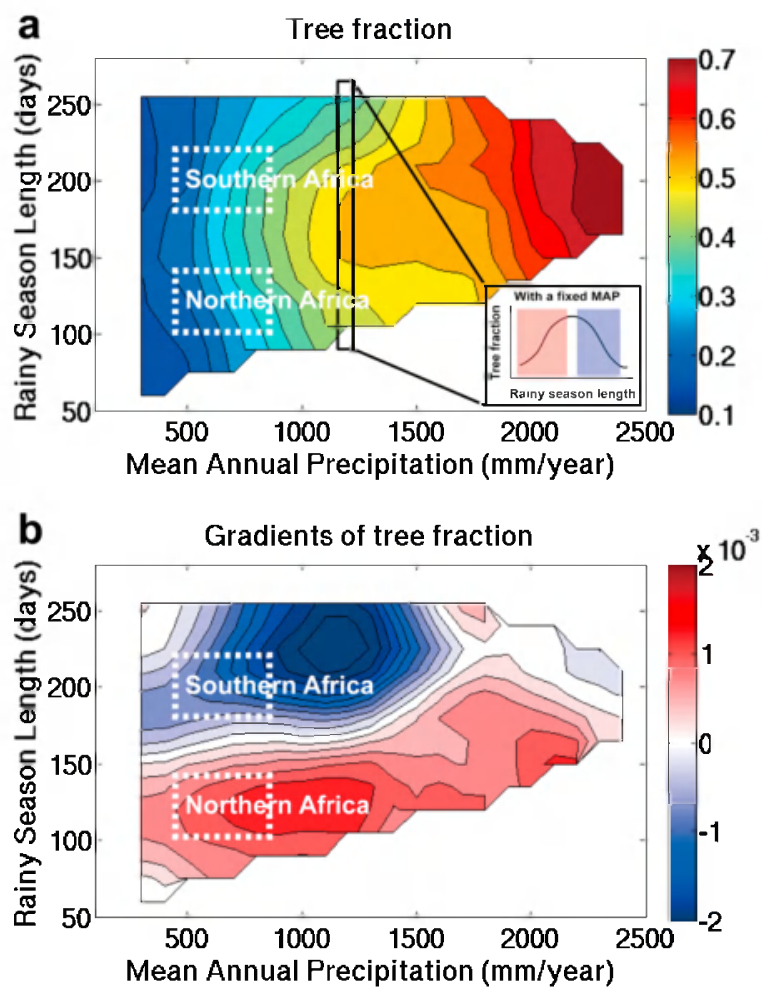

Figure 8. (a) Tree fraction as a function of both mean annual precipitation and rainy season length for the African domain. (b) Changes in tree fraction with rainy season length $(\% / d)$. Two dashed rectangular regions in both panels are correspondent to the two savanna regions shown in Figure S7 in the supporting information. The inset in Figure 8a presents a conceptual illustration of the nonlinear impacts of rainy season length on tree fraction cover at a fixed MAP, and the red and blue shading refer to the positive and negative sensitivities, which are consistent with the color shadings in Figure 8b.

regional pattern of increasing optimal length with increasing mean annual precipitation. We also find that with the similar total rainfall amount $(400-800 \mathrm{~mm} / \mathrm{yr})$ but different rainy season lengths, northern African savannas $\left(12^{\circ} \mathrm{N}-16^{\circ} \mathrm{N}\right.$ ) and southern African savannas (south of $22^{\circ} \mathrm{S}$ ) show distinctive responses (Figure S7 in the supporting information). From the hydrological perspective, northern Africa has a much shorter rainy season length and much more intense rainfall than regions in southern Africa (Figure 57). Thus, northern Africa savannas, correspondent to the rectangular space in Figure 8, would benefit from increasing rainy season length as a means for distributing rainfall and supporting vegetation growth over a longer period; the increase in rainy season length would thus improve the rainfall use efficiency and subsequently increase tree fractional cover. In contrast, southern African savannas, correspondent to the other identified regions in Figure 8, have a characteristically longer growing season length, and further increases in rainy season length would result in a reduced fractional tree cover.

We also find that most African woodlands show a positive sensitivity of tree fraction to increasing rainy season length; i.e., rainy seasons in these areas are generally below their optimal length, and rainfall is not maximized for the growth of woody species. Thus, increasing rainy season length, i.e., to spread the same amount of total annual rainfall for a longer period, would promote an increase in tree fractional cover in these areas.

\section{Discussion}

\subsection{Added Value of VOD in Studying Savanna Phenology}

VOD represents the whole-canopy water content and biomass [Jones et al., 2012], and we find the inclusion of it with the more traditional NDVI metric from optical-NIR remote sensing improved the understanding of LSP 
dynamics for different vegetation properties in this study. Coupling VOD and NDVI illuminates distinctive phenology responses in grassland and woodland systems that may enable the separation of relative tree/ grass contributions to the coarse-resolution remote sensing signal [Guan et al., 2012]. Further study of the VOD parameter, including use of variable microwave frequency retrievals in vegetation monitoring and modeling, should be encouraged for characterizing vegetation aboveground biomass changes.

\subsection{Dry Season Water Use Mechanisms for Explaining Woodland Phenology}

Our results indicate that tropical woodlands generally green-up before the onset of rainy season and also keep active in the early dry season. It does not mean that early leaf flush does not occur elsewhere (in the Acacias of the southern Kruger Park, for example), but it may only happen in a smaller fraction of total tree cover, and perhaps the duration of prerainfall leaf flush is less [e.g., Archibald and Scholes, 2007]. The two major possible mechanisms include (1) access and use of subsurface water storage deeper than $1 \mathrm{~m}$ by relatively deep rooted tropical deciduous trees and (2) stem-water reserve stored in tree trucks and roots. Though in this study we could not fully answer which dominating mechanism function at a specific region due to the lack of stem-water measurements, we find some large-scale evidence to possibly support the first mechanism. When the simulated shallow-layer soil moisture (within $1 \mathrm{~m}$ depth) is depleted during dry season, subsurface storage indicated from GRACE observations is still being withdrawn, which potentially can satisfy water needs for woody vegetation. This finding is consistent with some previous studies of tropical deciduous trees [Oliveira et al., 2005], which show that many tropical deciduous forests have deep roots and are capable of accessing deeper groundwater sources.

Regardless of which mechanisms, our results indicate that only using soil moisture thresholds as the phenological triggers in tropical deciduous forests (e.g., in Lund-Potsdam-Jena Model [Sitch et al., 2003] and Community Land Model [Levis et al., 2004]) may not be sufficient to characterize forest canopy phenology in these systems. Thus, for tropical deciduous forests, explicitly incorporating a groundwater-vegetation interactive component or stem-water storage mechanism may be essential to correctly simulate vegetation dynamics in these ecosystems.

\subsection{Prediction of Grassland and Woodland Phenology From Rainy Season Timing}

Our results confirm the previous modeling study that rainy season timing strongly controls grassdominated savanna phenology. Our results also indicate that African woodlands have much less interannual variability in phenological timing than grasslands, and that their growing seasons can extend beyond the rainy season (i.e., early green-ups and delayed senescence). Though the rainy season overlaps with the growing season, it is not coincident with the onset and end of the growing season in African woodlands. The end of the rainy season appears to correspond with the end of canopy maturity (i.e., start of senescence) as indicated from the NDVI signal and also with the timing of peak biomass indicated from the VOD signal. The potential factors controlling African woodland phenology are not obvious from our analysis. Radiationrelated factors, e.g., photoperiod or insolation [Borchert et al., 2005; Yeang, 2007], or atmospheric water demands (vapor pressure deficit [Do et al., 2005; Seghieri et al., 2012a, 2012b]) have been proposed as possible triggers of canopy phenology in these regions, and some of these factors (e.g., photoperiod or insolation) have almost no interannual variability, which mirror the low interannual variability in tropical tree phenology. Further exploration on this topic is needed, especially field data related to both canopy phenology and hydrological variables in tropical deciduous forests.

\subsection{Rainy Season Length and Its Ecological Significance}

Our result provides a possible empirical evidence to support the modeling study for the nonlinear response of rainy season on vegetation productivity. It is worth noting that the emphasis of this possible hydrologydriven nonlinear response does not devalue other factors for savanna dynamics and tree fraction cover but rather highlights some overlooked aspect that same rainfall, but arrive in a different way, may lead to diverse ecological responses. If we are convinced of the importance of rainy season length on ecosystem structure and function, we need to recognize that how well climate models predict future changes in rainy season length is also largely understudied, and the implications of these changes to future ecosystem productivity and biome distribution are also largely unknown. Thus, it is imperative to include rainy season length and other rainy season characteristics in assessing the future ecohydrological changes, especially in water-limited ecosystems. 


\subsection{Limitations of Coarse-Resolution Remote Sensing in Studying Savanna Phenology}

While there are many advantages in using relatively coarse spatial resolution $(>100 \mathrm{~m})$ satellite remote sensing and hydrological modeling in studying African savanna phenology, a major drawback of these methods is the lack of resolution in differentiating the relative contributions of grasses and trees at the pixel level. This limitation hinders the interpretation of savanna phenology [Archibald and Scholes, 2007], e.g., whether the early green-up phenomenon is from grasses/shrubs or from trees, and the associated environmental cues driving these changes. Thus, remote sensing at finer spatial resolutions is needed for resolving potentially contrasting grassland and woody vegetation dynamics in savanna ecosystems. Recent progress in unmanned aerial vehicle-based sensing systems [e.g., Dandois and Ellis, 2013] and the "near-surface remote sensing" (e.g., PhenoCam network [Richardson et al., 2009]) may provide possible avenues to resolve subgrid-scale heterogeneity in savanna ecology and phenology. Another possible avenue is to increase the coverage of ground observation networks to more effectively link remote sensing measurements with ground truth. Recently, much progress has been made in developing relatively dense phenological observation networks in North America (e.g., USA National Phenology Network) and Europe (e.g., European Phenology Network). A similar network is currently unavailable over Africa but could provide an effective means for LSP validation and analysis and improved understanding of regional phenology.

\section{Conclusion}

Understanding relationships between the hydrological cycle and land surface phenology in African savannas and woodlands has fundamental significance for modeling tropical vegetation dynamics, quantifying their carbon budget and predicting their future response to climate changes. This paper uses multiple data sets from satellite observations and hydrological model simulations to empirically explore temporal relationships between the hydrological cycle and regional phenology, and the nonlinear impact of rainy season length on ecosystem structure. The key findings from this study are summarized below:

1. We find that the annual growing season onset temporally lags and can be effectively predicted by the rainy season onset for African grasslands.

2. Most African woodlands differ from grasslands and tend to have early green-up before the rainy season onset. African woodlands also show variable duration of senescence following the end of the rainy season, which has a nonlinear correlation with tree fraction cover; interannual variability in woodland phenological phases is relatively small compared to African grasslands. We find some evidence to support the subsurface water use through deep root system ( $>1 \mathrm{~m}$ depth) to maintain dry season vegetation activity.

3. We empirically find the rainy season length has strong nonlinear impacts on tree fractional cover in the annual rainfall range from 600 to $1800 \mathrm{~mm} / \mathrm{yr}$, and there exists a rainy season optimal length for maximizing tree fractional cover at different rainfall regimes.

Acknowledgments

K. Guan and E.F. Wood acknowledge the supports from the NASA NESSF fellowship and Walbridge Graduate Funds from Princeton Environmental Institute of Princeton University. K.K. Caylor acknowledges the financial supports from the National Science Foundation through the grant EAR-0847368. J. Kimball was supported through the NASA MEaSUREs (Making Earth System data records for Use in Research Environments) program.

\section{References}

AGRHYMET (1996), Méthodologie de suivi des zones à risque, Tech. Rep., AGRHYMET FLASH, Bulletin de Suivi de laCampagneAgricole au Sahel, Centre Regional AGRHYMET, Niamey, Niger.

Archibald, S., and R. Scholes (2007), Leaf green-up in a semi-arid African savanna-Separating tree and grass responses to environmental cues, J. Veg. Sci., 18, 583-594.

Archibald, S., D. P. Roy, B. W. Van Wilgen, and R. J. Scholes (2009), What limits fire? An examination of drivers of burnt area in Southern Africa, Global Change Biol., 15, 613-630.

Biasutti, M., and A. H. Sobel (2009), Delayed Sahel rainfall and global seasonal cycle in a warmer climate, Geophys. Res. Lett., 36, L23707, doi:10.1029/2009GL041303.

Bie, S. D., P. Ketner, M. Paasse, and C. Geerling (1998), Woody plant phenology in the West Africa savanna, J. Biogeogr., 25, 883-900. Bonan, G. (2008), Ecological Climatology: Concepts and Applications, 2nd ed., Cambridge Univ. Press, Cambridge, U. K.

Borchert, R. (1994), Soil and stem water storage determine phenology and distribution of tropical dry forest trees, Ecology, 75(5), 1437-1449. Borchert, R., S. S. Renner, Z. Calle, D. Navarrete, A. Tye, L. Gautier, R. Spichiger, and P. von Hildebrand (2005), Photoperiodic induction of synchronous flowering near the equator, Nature, 433, 627-629.

Brown, M. E., and K.M. de Beurs (2008), Evaluation of multi-sensor semi-arid crop season parameters based on NDVI and rainfall, Remote Sens. Environ., 112, 2261-2271.

Brown, M. E., K. de Beurs, and A. Vrieling (2010), The response of African land surface phenology to large scale climate oscillations, Remote Sens. Environ., 114(10), 2286-2296.

Brown, M. E., K. de Beurs, and M. Marshall (2012), Global phenological response to climate change in crop areas using satellite remote sensing of vegetation, humidity and temperature over 26 years, Remote Sens. Environ., 126, 174-183.

Camberlin, P., N. Martiny, N. Philippon, and Y. Richard (2007), Determinants of the interannual relationships between remote sensed photosynthetic activity and rainfall in tropical Africa, Remote Sens. Environ., 106, 199-216. 
Chen, J. M., F. Deng, and M. Chen (2006), Locally adjusted cubic-spline capping for reconstructing seasonal trajectories of a satellite-derived surface parameter, IEEE Trans. Geosci. Remote Sens., 44(8), 2230-2238.

Chidumayo, E. N. (1994), Phenology and nutrition of Miombo woodland trees in Zambia, Trees, 9, 67-72.

Cook, K. H. (2000), The South Indian convergence zone and interannual rainfall variability over Southern Africa, J. Clim., 13, $3789-3804$.

Dandois, J. P., and E. C. Ellis (2013), High spatial resolution three-dimensional mapping of vegetation spectral dynamics using computer vision, Remote Sens. Environ., 136, 259-276.

Do, F. C., V. A. Goudiaby, O. Gimenez, A. L. Diagne, M. Diouf, A. Rocheteau, and L. E. Akpo (2005), Environmental influence on canopy phenology in the dry tropics, For. Ecol. Manage., 215, 319-328.

Do, F. C., A. Rocheteau, A. Diagne, V. Goudiaby, A. Granier, and J. Lhomme (2008), Stable annual pattern of water use by Acacia tortilisin Sahelian Africa, Tree Physiol., 28, 95-104.

Feng, X., G. Vico, and A. Porporato (2012), On the effects of seasonality on soil water balance and plant growth, Water Resour. Res., 48, W05543, doi:10.1029/2011WR011263.

Fierer, N., and J. P. Schimel (2002), Effects of drying-rewetting frequency on soil carbon and nitrogen transformations, Soil Biol. Biochem., 34 , 777-787.

Fuller, D., and S. Prince (1996), Rainfall and foliar dynamics in tropical southern Africa: Potential impacts of global climatic change on savanna vegetation, Clim. Change, 33, 69-96.

Garcia, D. (2010), Robust smoothing of gridded data in one and higher dimensions with missing values, Comput. Stat. Data Anal., 54, $1167-1178$

Giannini, A., M. Biasutti, I. M. Held, and A. H. Sobel (2008), A global perspective on African climate, Clim. Change, 90, 359-383.

Guan, K., E. F. Wood, and K. K. Caylor (2012), Multi-sensor derivation of regional vegetation fractional cover in Africa, Remote Sens. Environ., $124,653-665$.

Guan, K., A. Wolf, D. Medvigy, K. Caylor, M. Pan, and E. Wood (2013), Seasonal coupling of canopy structure and function in African tropical forests and its environmental controls, Ecosphere, 4(3), 35.

Guan, K., D. Medvigy, E. F. Wood, K. K. Caylor, S. Li, and S.-J. Jeong (2014), Deriving vegetation phenological time and trajectory information over Africa using SEVIRI daily LAl, IEEE Trans. Geosci. Remote Sens., 53(2), 1113-1130.

Hansen, M. C., R. S. DeFries, J. R. G. Townshend, M. Carroll, C. Dimiceli, and R. A. Sohlberg (2003), Global percent tree cover at a spatial resolution of 500 meters: First results of the MODIS vegetation continuous fields algorithm, Earth /nteract., 7, 1-15, doi:10.1175/1087-3562 (2003)007<0001:GPTCAA >2.0.CO;2.

Heumann, B., J. Seaquist, L. Eklundh, and P. Jonsson (2007), AVHRR derived phenological change in the Sahel and Soudan, Africa, 1982-2005, Remote Sens. Environ., 108, 385-392.

Higgins, S. I., and S. Scheiter (2012), Atmospheric $\mathrm{CO}_{2}$ forces abrupt vegetation shifts locally, but not globally, Nature, 488, 209-212

Higgins, S. I., M. D. Delgado-Cartay, E. C. February, and H. J. Combrink (2011), Is there a temporal niche separation in the leaf phenology of savanna trees and grasses?, J. Biogeogr., 38, 2165-2175.

Huffman, G. J., D. T. Bolvin, E. J. Nelkin, D. B. Wolff, R. F. Adler, K. P. Bowman, and E. F. Stocker (2007), The TRMM Multisatellite Precipitation Analysis (TMPA): Quasi-global, multiyear, combined-sensor precipitation estimates at fine scales, J. Hydrometeorol., $8,38-55$.

Huxman, T. E., et al. (2004), Convergence across biomes to a common rain-use effeciency, Nature, 429, 651-654.

Jackson, T. J. (1993), Measuring surface soil moisture using passive microwave remote sensing, Hydrol. Processes, 7, 139-152.

Jones, L. A., and J. S. Kimball (2010), Daily global land surface parameters derived from AMSR-E, Tech. Rep., Natl. Snow and Ice Data Cent., Digital media, Boulder, Colo. [Available at http://nsidc.org/data/nsidc-0451.html.]

Jones, L. A., C. R. Ferguson, J. S. Kimball, K. Zhang, S. K. Chan, K. C. McDonald, E. G. Njoku, and E. F. Wood (2010), Daily land surface air temperature retrieval from AMSR-E: Comparison with AIRS/AMSU, IEEE J. Sel. Top. Appl. Earth Obs. Remote Sens., 3(1), 111-123.

Jones, M. O., L. A. Jones, J. S. Kimball, and K. C. McDonald (2011), Satellite passive microwave remote sensing for monitoring global land surface phenology, Remote Sens. Environ., 115(4), 1102-1114.

Jones, M. O., J. S. Kimball, L. A. Jones, and K. C. McDonald (2012), Satellite passive microwave detection of North America start of season, Remote Sens. Environ., 123, 324-333.

Jones, M. O., J. S. Kimball, and L. A. Jones (2013a), Satellite microwave detection of boreal forest recovery from the extreme 2004 wildfires in Alaska and Canada, Global Change Biol, 19(10), 3111-3122.

Jones, M. O., J. S. Kimball, E. E. Small, and K. M. Larson (2013b), Comparing land surface phenology derived from satellite and GPS network microwave remote sensing, Int. J. Biometeorol., doi:10.1007/s00484-013-0726-z.

Lehmann, C. E. R., S. A. Archibald, W. A. Hoffmann, and W. J. Bond (2011), Deciphering the distribution of the savanna biome, New Phytol, 191 , $197-209$.

Levis, S., G. B. Bonan, M. Vertenstein, and K. W. Oleson (2004), The Community Land Model's Dynamic Global Vegetation Model. (CLM-DGVM): Technical description and user's guide, Tech. Rep., NCAR.

Liang, X., D. P. Lettenmaier, E. F. Wood, and S. Burges (1994), A simple hydrologically based model of land surface water and energy fluxes for general circulation models, J. Geophys. Res., 99(D7), 14,415-14,428, doi:10.1029/94JD00483.

Linderman, M., P. Rowhani, D. Benz, S. Serneels, and E. F. Lambin (2005), Land-cover change and vegetation dynamics across Africa, J. Geophys. Res., 110, D12104, doi:10.1029/2004JD005521.

Lloyd, J., M. I. Bird, L. Vellen, A. C. Miranda, E. M. Veenendaal, G. Djagbletey, H. S. Miranda, G. Cook, and G. D. Farquhar (2008), Contributions of woody and herbaceous vegetation to tropical savanna ecosystem productivity: A quasi-global estimate, Tree Physiol., 28, 451-468.

Long, D. (2001), BYU daily browse images of QuikSCAT sigma-0 measurements, Tech. Rep., Brigham Young University. [Available at $\mathrm{ftp}: / / \mathrm{ftp} . \mathrm{scp}$. byu.edu/docs/guideSigBrw.html.]

Marengo, J. A., B. Liebmann, V. E. Kousky, N. P. Filizola, and I. C. Wainer (2001), Onset and end of the rainy season in the Brazilian Amazon Basin, J. Clim., 14, 833-852.

Martiny, N., P. Camberlin, Y. Richard, and N. Philippon (2006), Compared regimes of NDVI and rainfall in semi-arid regions of Africa, int. J. Remote Sens., 27(23), 5201-5223.

Maurer, E. P., A. W. Wood, J. C. Adam, D. P. Lettenmaier, and B. Nijssen (2002), A long-term hydrologically based dataset of land surface fluxes and states for the conterminous United States, J. Clim., 15, 3237-3251.

Mayaux, P., E. Bartholome, S. Fritz, and A. Belward (2004), A new land-cover map of Africa for the year 2000, J. Biogeogr., 31, 861-877.

McHugh, M. J., and J. C. Rogers (2001), North Atlantic Oscillation influence on precipitation variability around the Southeast African convergence zone, J. Clim., 14, 3631-3642.

Morisette, J., et al. (2009), Tracking the rhythm of the seasons in the face of global change: Phenological research in the 21 st century, Front. Ecol. Environ., 7(5), 253-260. 
Myneni, R. B., C. D. Keeling, C. J. Tucker, G. Asrar, and R. R. Nemani (1997), Increased plant growth in the northern high latitudes from 1981 to 1991, Nature, 386, 698-702.

Nemani, R. R., C. D. Keeling, H. Hashimoto, W. M. Jolly, S. C. Piper, C. J. Tucker, R. B. Myneni, and S. W. Running (2003), Climate-driven increases in global terrestrial net primary production from 1982 to 1999 , Science, 300, 1560-1563.

Nicholson, S. E. (1996), A review of climate dynamics and climate variability in eastern Africa, in The Limnology, Climatology and Paleoclimatology of the East African Lakes, edited by T. C. Johnson and E. O. Odada, pp. 25-56, Gordon and Breach, New York.

Nijssen, B., R. Schnur, and D. P. Lettenmaier (2001), Global retrospective estimation of soil moisture using the variable infiltration capacity land surface model, 1980-93, J. Clim., 14, 1790-1808.

Njoku, E. G., and D. Entekhabi (1996), Passive microwave remote sensing of soil moisture, J. Hydrol., 184, $101-129$.

Noy-Meir, I. (1973), Desert ecosystems: Environment and producers, Annu. Rev. Ecol. Syst., 4, $25-51$.

Oliveira, R. S., L. Bezerra, E. A. Davidson, F. Pinto, C. A. Klink, D. C. Nepstad, and A. Moreira (2005), Deep root function in soil water dynamics in Cerrado savannas of central Brazil, Funct. Ecol., 19, 574-581.

Pan, M., H. Li, and E. Wood (2010), Assessing the skill of satellite-based precipitation estimates in hydrologic applications, Water Resour. Res., 46, W09535, doi:10.1029/2009WR008290

Pan, M., A. K. Sahoo, T. J. Troy, R. K. Vinukollu, J. Sheffield, and E. F. Wood (2012), Multisource estimation of long-term terrestrial water budget for major global river basins, J. Clim., 25, 3191-3206.

Peel, M. C., B. L. Finlayson, and T. A. McMahon (2007), Updated world map of the Kuppen-Geiger climate classification, Hydrol. Earth Syst. Sci., $11,1633-1644$.

Philippon, N., E. Mougin, L. Jarlan, and P.-L. Frison (2005), Analysis of the linkages between rainfall and land surface conditions in the West African monsoon through CMAP, ERS-WSC, and NOAA-AVHRR data, J. Geophys. Res., 110, D24115, doi:10.1029/2005JD006394.

Piao, S., et al. (2008), Net carbon dioxide losses of northern ecosystems in response to autumn warming, Nature, 457(3), $49-53$.

Pineda-Garcia, F., H. Paz, and F. C. Meinzer (2012), Drought resistance in early and late secondary successional species from a tropical dry forest: The interplay between xylem resistance to embolism, sapwood water storage and leaf shedding, Plant Cell Environ., 36(2), 405-418.

Pokhrel, Y. N., Y. Fan, G. Miguez-Macho, P. J.-F. Yeh, and S.-C. Han (2013), The role of groundwater in the Amazon water cycle: 3 . Influence on terrestrial water storage and comparison with GRACE, J. Geophys. Res. Atmos., 118, 3233-3244, doi:10.1002/jgrd.50335.

Richardson, A. D., B. H. Baswell, D. Y. Hollinger, J. P. Jenkins, and A. V. Ollinger (2009), Near-surface remote sensing of spatial and temporal variation in canopy phenology, Ecol. Appl., 19(6), 1417-1428.

Richardson, A.D., et al. (2010), Influence of spring and autumn phenological transitions on forest ecosystem productivity, Philos. Trans. R. Soc. $B, 365,3227-3246$.

Richardson, A. D., T. F. Keenan, M. Migliavacca, Y. Ryu, O. Sonnentag, and M. Toomey (2013), Climate change, phenology, and phenological control of vegetation feedbacks to the climate system, Agric. For. Meteorolog, 169, 156-173.

Rodell, M., and J. Famiglietti (2002), The potential for satellite-based monitoring of groundwater storage changes using GRACE: The High Plains aquifer, Central US, J. Hydrol., 263(1-4), 245-256.

Rodell, M., B. F. Chao, A. Y. Au, J. S. Kimball, and K. C. McDonald (2005), Global biomass variation and its geodynamic effects: 1982-98, Earth Interact., 9, 1-19, doi:10.1175/El126.1.

Rohr, T., S. Manzoni, X. Feng, R. S. C. Menezes, and A. Porporato (2013), Effect of rainfall seasonality on carbon storage in tropical dry ecosystems, J. Geophys. Res. Biogeosci., 118, 1156-1167, doi:10.1002/jgrg.20091.

Roupsard, O., A. Ferhi, A. Granier, F. Pallo, D. Depommier, B. Mallet, H. I. Joly, and E. Dreyer (1999), Reverse phenology and dry-season water uptake by Faidherbia albida (Del.) A. Chev. in an Agroforestry Parkland of Sudanese West Africa, Funct. Ecol., 13(4), 460-472.

Sarmiento, G. (1984), The Ecology of Neotropical Savannas, Harvard Univ. Press, Cambridge, Mass.

Scanlon, T. M., K. K. Caylor, S. Manfreda, S. A. Levin, and I. Rodriguez-Iturbe (2005), Dynamic response of grass cover to rainfall variability: Implications for the function and persistence of savanna ecosystems, Adv. Water Resour., 28, 291-302.

Scheiter, S., and S. I. Higgins (2009), Impacts of climate change on the vegetation of Africa: An adaptive dynamic vegetation modelling approach, Global Change Biol., 15, 2224-2246.

Schenk, H. J., and R. B. Jackson (2002), The global biogeography of roots, Ecol. Monogr., 72(3), 31 1-328.

Schimper, A. F. W. (1903), Plant Geography on a Physiological Basis, Clarendon Press, Oxford, U. K.

Scholes, R. J., and S. R. Archer (1997), Tree-grass interactions in savannas, Annu. Rev. Ecol. Syst., 28, 517-544.

Seghieri, J., C. Floret, and R. Pontanier (1995), Plant phenology in relation to water availability: Herbaceous and woody species in the savannas of northern Cameroon, J. Trop. Ecol., 11, 237-254.

Seghieri, J., J. Carreau, N. Boulain, P. D. Rosnay, M. Arjounin, and F. Timouk (2012a), Is water availability really the main environmental factor controlling the phenology of woody vegetation in the central Sahel?, Plant Ecol., 213, 861-870.

Seghieri, J., F. C. Do, J.-L. Devineau, and A. Fournier (2012b), Phenology of woody species along the climatic gradient in west tropical Africa, in Phenology and Climate Change, edited by X. Zhang, pp. 143-178, IntechOpen, Rijeka, Croatia, doi:10.5772/33729.

Sellers, P. J., J. A. Berry, G. J. Collatz, C. B. Field, and E. G. Hall (1992), Canopy reflectance, photosynthesis, and transpiration. III. A reanalysis using improved leaf models and a new canopy integration scheme, Remote Sens. Environ., 42, 187-216.

Sheffield, J., and E. F. Wood (2007), Characteristics of global and regional drought, 1950-2000: Analysis of soil moisture data from off-line simulation of the terrestrial hydrologic cycle, J. Geophys. Res., 112, D17115, doi:10.1029/2006JD00828.

Sheffield, J., G. Goteti, and E. F. Wood (2006), Development of a 50-year high-resolution global dataset of meteorological forcings for land surface modeling, J. Clim., 19, 3088-3111.

Shongwe, M. E., G. J. van Oldenborgh, B. J. J. M. van den Hurk, B. de Boer, C. A. S. Coelho, and M. K. van Aalst (2009), Projected changes in mean and extreme precipitation in Africa under global warming. Part I: Southern Africa, J. Clim., 22, 3819-3837.

Sitch, S., et al. (2003), Evaluation of the terrestrial carbon cycle, future plant geography and climate-carbon cycle feedbacks using five Dynamic Global Vegetation Models (DGVMs), Global Change Biol., 14(9), 2015-2039.

Solano, R., K. Didan, A. Jacobson, and A. Huete (2010), MODIS vegetation index user's guide (Collection 5). [Available at http://vip.arizona.edu/ documents/MODIS/MODIS_VI_UsersGuide_01_2012.pdf.]

Staver, A. C., S. Archibald, and S. A. Levin (2011), The global extent and determinants of savanna and forest as alternative biome states, Science, 334, 230-232.

Stöckli, R., T. Rutishauser, I. Baker, M. A. Liniger, and A. S. Denning (2011), A global reanalysis of vegetation phenology, J. Geophys. Res., 116, G03020, doi:10.1029/2010JG001545.

Strassberg, G., B. R. Scanlon, and D. Chambers (2009), Evaluation of groundwater storage monitoring with the GRACE satellite: Case study of the High Plains aquifer, central United States, Water Resour. Res., 45, W05410, doi:10.1029/2008WR006892. 
Swenson, S., and J. Wahr (2006), Post-processing removal of correlated errors in GRACE data, Geophys. Res. Lett., 33, L08402, doi:10.1029/ 2005GL025285.

Tapley, B. D., S. Bettadpur, J. C. Ries, P. F. Thompson, and M. M. Watkins (2004), GRACE measurements of mass variability in the Earth system, Science, 305, 503-505.

Tateishi, R., and M. Ebata (2004), Analysis of phenological change patterns using 1982-2000 Advanced Very High Resolution Radiometer (AVHRR) data, int. J. Remote Sens., 25(12), 2287-2300.

Trenberth, K. E., A. Dai, R. M. Rasmussen, and D. B. Parsons (2003), The changing character of precipitation, Bull. Am. Meteorol. Soc., 84, $1205-1217$.

Ulaby, F., R. K. Moore, and A. K. Fung (1982), Microwave Remote Sensing: Active and Passive, 2, Radar Remote Sensing and Surface Scattering and Emission Theory, Addison-Wesley, Reading, Mass.

van Schaik, C. P., J.W. Terborgh, and S. J. Wright (1993), The phenology of tropical forests: Adaptive significance and consequences for primary consumers, Annu. Rev. Ecol. Syst., 24, 353-377.

Vermote, E. F., S. Y. Kotchenova, and J. P. Ray (2011), MODIS surface reflectance user's guide, Tech. Rep., MODIS Land Surface Reflectance Science Computing Facility. [Available at http://modis-sr.Itdri.org/products/MOD09 UserGuide v1 3.pdf.]

Vrieling, A., J. de Leeuw, and M. Y. Said (2013), Length of growing period over Africa: Variability and trends from 30 years of NDVI time series, Remote Sens., 5(2), 982-1000.

Wagner, W., G. Lemoine, and H. Rott (1999), A method for estimating soil moisture from ERS scatterometer and soil data, Remote Sens. Environ., 70, 191-207.

Walter, H. (1939), Grasland, Savanne und Busch der arideren Teile Afrikas in ihrer ökologischen Bedingtheit, Jahrb Wiss Bot, 87, 750-860.

Wang, B., and LinHo (2002), Rainy season of the Asian-Pacific summer monsoon, J. Clim., 15, 386-398.

Ward, D., K. Wiegand, and S. Getzin (2013), Walter's two-layer hypothesis revisited: Back to the roots!, Oecologia, 172, 617-630.

Weltzin, J. F., et al. (2003), Assessing the response of terrestrial ecosystems to potential changes in precipitation, BioScience, 53(10), 941-952.

White, M., et al. (2009), Intercomparison, interpretation, and assessment of spring phenology in North America estimated from remote sensing for 1982-2006, Global Change Biol., 15, 2335-2359.

Yeang, H.-Y. (2007), The sunshine-mediated trigger of synchronous flowering in the tropics: The rubber tree as a study model, New Phytol., $176,730-735$

Zhang, X., M. A. FriedI, C. B. Schaaf, A. H. Strahler, J. C. Hodges, F. Gao, B. C. Reed, and A. Huete (2003), Monitoring vegetation phenology using MODIS, Remote Sens. Environ., 84, 471-475.

Zhang, X., M. A. Friedl, C. B. Schaaf, A. H. Strahler, and Z. Liu (2005), Monitoring the response of vegetation phenology to precipitation in Africa by coupling MODIS and TRMM instruments, J. Geophys. Res., 110, D12103, doi:10.1029/2004JD005263.

Zhou, L., C. J. Tucker, R. Kaufman, D. Slayback, N. V. Shabanov, and R. B. Myneni (2001), Variations in northern vegetation activity inferred from satellite data of vegetation index during 1981 to 1999, J. Geophys. Res., 106(D17), 20,069-20,083, doi:10.1029/2000JD000115. 